\title{
Seroprevalence of rubella and immunogenicity following rubella vaccination in adolescent girls in India
}

\author{
Hitt J Sharma ${ }^{1}$, Vasant S Padbidri ${ }^{2}$, Subhash V Kapre ${ }^{1}$, Suresh S Jadhav ${ }^{1}$, Rajeev M Dhere ${ }^{1}$, \\ Sameer S Parekh ${ }^{1}$, Ashok D Dudhane ${ }^{2}$, Sunil D Shewale ${ }^{1}$, Gajanan S Namjoshi ${ }^{3}$ \\ ${ }^{1}$ Serum Institute of India Ltd., Pune-411028, India \\ ${ }^{2}$ King Edward Memorial Hospital Research Centre, Pune-411011, India \\ ${ }^{3}$ Earlier with Serum Institute of India Ltd., Pune-411028, India
}

\begin{abstract}
Introduction: Serologic surveys conducted in different countries indicate that rubella is a worldwide infection. Several such sero surveys conducted in India have also confirmed that $6-47 \%$ of women are susceptible to rubella infection. The current study was conducted on 1,329 female adolescents in 12 districts of Maharashtra, India, to assess their serological status in terms of rubella exposure.

Methodology: After enrollment, a pre-vaccination blood sample was collected from the participants followed by rubella vaccination (R-vac). Adverse events were monitored for the next 6-8 weeks, at which time a post-vaccination sample was collected.

Results: Pre-vaccination rubella immunity was higher in the urban $(80.2 \%)$ population compared to the rural (73.1\%) population. Following R-vac vaccination, out of 1,159 participants who completed the study, all (100\%) in the urban and $99.5 \%$ of participants in the rural area developed antibodies against rubella.

Conclusion: Substantial numbers of women reach childbearing age without immunity against rubella and thus are at a risk of passing the infection to their fetuses, who can then develop subsequent congenital defects leading to congenital rubella syndrome (CRS). An immunization policy recommending vaccination with rubella or rubella containing vaccine is highly desirable to prevent rubella and CRS.
\end{abstract}

Key words: rubella; serological survey; immunogenicity; safety

J Infect Dev Ctries 2011; 5(12):874-881.

(Received 11 January 2011 - Accepted 22 February 2011)

Copyright (C) 2011 Sharma et al. This is an open-access article distributed under the Creative Commons Attribution License, which permits unrestricted use, distribution, and reproduction in any medium, provided the original work is properly cited.

\section{Introduction}

Although rubella vaccination has reduced the incidence of rubella virus infection substantially, more than 100,000 children worldwide are still born with CRS each year, most of them in developing countries [1]. During 2009, a total of 121,344 rubella cases were reported from 167 member states to the World Health Organization (WHO), an $82 \%$ decrease from the 670,894 cases reported in 2000 from 102 member states. Though the majority of women are immune by the time they reach childbearing age due to childhood exposure or rubella virus infection, periodic epidemics still occur among children and spread to involve the small portion of susceptible adult women, leading to epidemics of CRS [2-3]. Several sero epidemiological surveys for rubella antibody have shown that a substantial number of women reach childbearing age without acquiring natural immunity to rubella and thus these females are susceptible to rubella virus infection during pregnancy [4-6]. As the vaccine-induced immunity is generally assumed to be lifelong, subjects are presumed to be immune if they have documentation of vaccination with a single dose of measles, mumps, rubella (MMR) vaccine or other live rubella containing vaccine administered on or after their first birthday or have laboratory evidence of immunity [78]. The presence of rubella specific $\operatorname{IgG}$ in an unvaccinated population is a long-term marker of previous rubella infection. This study was conducted to determine the incidence of rubella immunity in adolescent girls aged 12-15 years in both rural and urban areas of 12 districts in Maharashtra state, India.

\section{Methodology}

\section{Study design}

This Phase IV single-arm study was conducted in both rural and urban areas of 12 districts of Maharashtra, India, namely Ahmednagar, Beed, Dhule, Jalna, Kolhapur, Latur, Nasik, Nandurbar, 
Pune, Satara, Solapur, and Osmanabad to assess the incidence of rubella immunity in healthy school girls, aged 12-15 years.

\section{Human subject participation}

The study was conducted in accordance with good clinical practice guidelines issued in schedule $\mathrm{Y}$ and ICH-E6 and per the ethical principles for medical research mentioned in the Declaration of Helsinki (2008). The study commenced after receiving approval from the Institutional Ethics Committee, KEM Hospital Research Foundation, Pune, and permission from respective school principals. Written informed consent was obtained from the subjects' parents or legal guardians prior to screening and enrollment.

\section{Vaccinees}

Healthy schoolgirls aged 12 to 15 years, not suffering from any illness or any obvious health problems, not participating in any other clinical trial, and whose parents were willing to give written informed consent were included in the study. Exclusion criteria included girls with known rubella infection; history of receipt of rubella vaccine; history of significant and persistent hematological, hepatic, renal, cardiac, respiratory, neurological disorders or seizure; confirmed immunosuppression; or any acute ongoing disease.

\section{Vaccine (R-vac)}

$\mathrm{R}$-vac (rubella) vaccine, manufactured by the Serum Institute of India Ltd., Pune, India, was administered to girls who were enrolled, per eligibility criteria. The batch used in the study (i.e. batch no: ZA-40, Manufacture date: Apr 2008 and Expiry date: Mar 2010) was duly tested and cleared by the Central Drugs Laboratory, Kasauli, the National Control Laboratory in India. Each $0.5 \mathrm{ml}$ single dose of the reconstituted vaccine contains 1000 CCID50 of rubella virus (Wistar RA 27/3 strain) propagated on human diploid cells. The vaccine was stored at $2-8^{\circ} \mathrm{C}$.

\section{Study procedures}

Written, dated, and signed informed consent was obtained from the subjects' parents. After screening, a $2 \mathrm{ml}$ blood sample was drawn for serological evaluation, following which all subjects were administered a single $0.5 \mathrm{ml}$ dose of $\mathrm{R}$-vac vaccine subcutaneously, in the deltoid region of the upper arm. The subjects were closely observed for 30 minutes to monitor and manage any immediate adverse reaction. Diary cards in Marathi, the local vernacular language, or in English were issued to all the schoolgirls/parents/legal guardians and instructions for reporting adverse events were given. Additionally, subjects and parents were informed about their next scheduled visit. Social workers or school staff contacted the subject's parents (by telephone or by home visits) to determine the reasons for discontinuation of study, if any. On the second visit, 6 to 8 weeks post-vaccination, diary cards were reviewed and a second blood sample was collected.

\section{Serology}

For serological evaluation, standard enzyme linked immuno sorbent assay (ELISA) test was conducted at Manipal Acunova Ltd., Bangalore, a central laboratory accredited by the College of American Pathologists (CAP) and the National Accreditation Board for Testing Laboratories (NABL) of the Department of Science and Technology, Government of India. IgG rubella antibody level in the serum was determined at baseline (prevaccination) and at 6 to 8 weeks, post vaccination using the Euroimmun kit from Luebeck, Germany. The results were expressed as $\mathrm{IU} / \mathrm{ml}$. Based on the cut-off values mentioned in the kit literature, seroprotection was defined as anti rubella antibody concentrations $\geq 11 \mathrm{IU} / \mathrm{ml}$ by ELISA.

\section{Safety}

The vaccinees were observed for local and systemic adverse events including rare cases of anaphylaxis, if any. The solicited adverse events associated with rubella vaccine are pain, redness, swelling, nodule, rash, joint pain, muscle pain, lymphadenopathy. Parents and legal guardians were instructed to inform the school principal and/or study coordinator immediately about the occurrence of any serious adverse event.

Pain at injection site was designated as Grade 1 (present, but movement not affected), Grade 2 (discomfort, interferes with or limits arm movement) and Grade 3 (disabling, unable to move arm). For redness, swelling and nodule, the longest diameter was noted in millimeters. For fever (axillary temperature), highest temperature recorded in a day was noted in degree Celsius $\left({ }^{\circ} \mathrm{C}\right)$. To assess the relationship of the adverse event to the study vaccine, the WHO-UMC (WHO-Uppsala Monitoring Centre) causality assessment system was followed. 
Figure 1. Subject disposition

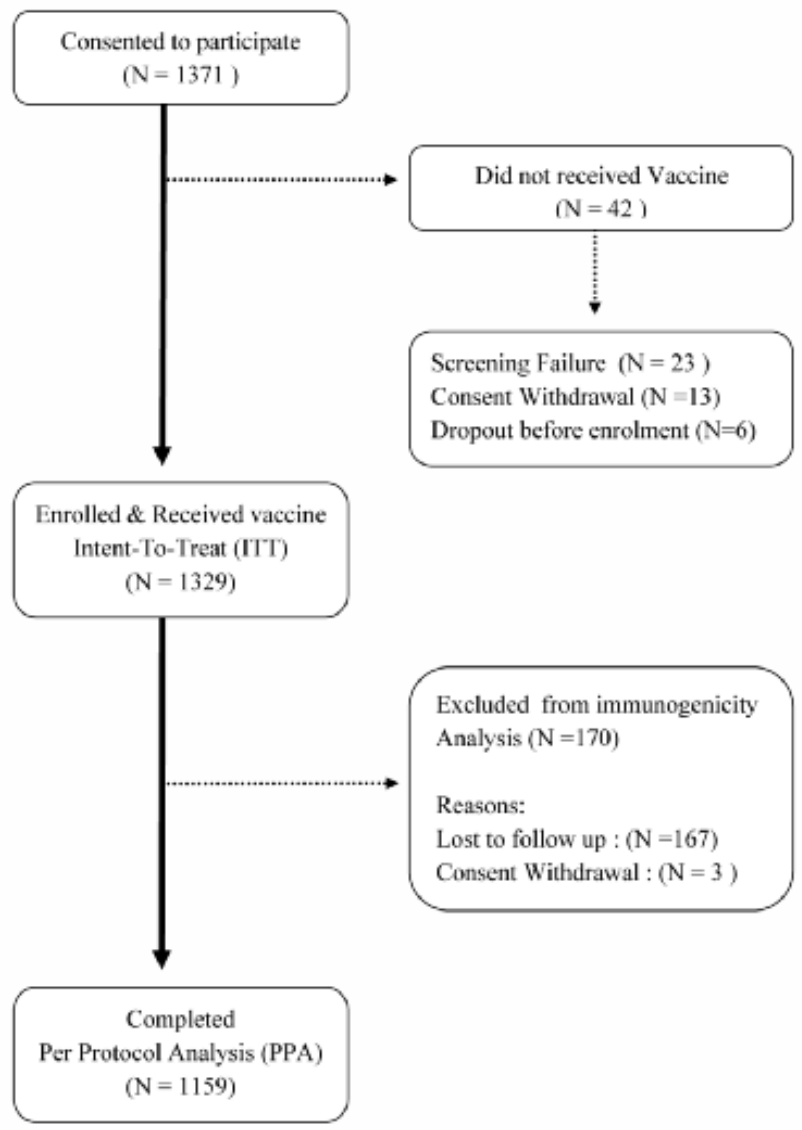

Accordingly, the terminology used for categorization was as follows: certain, probable/likely, possible, unlikely, conditional/unclassifiable, and unassessable.

\section{Results}

Parents of 1,371 subjects gave written informed consent for their daughters to participate in the study. On screening, 1,329 subjects were found eligible and enrolled in the study. Out of these 1,329 enrolled subjects, 167 subjects were lost to follow-up and the parents of three subjects withdrew their consent. No subject dropped out of the study due to adverse events caused by the vaccine. Thus the final evaluable sample size available for immunogenicity analysis was 1,159 subjects [Figure 1]. However, for safety evaluation, data of all 1,329 girls was analyzed.

\section{Baseline demography}

The baseline demographic characteristics (mean age, present weight and height, nutritional status, pulse rate, respiratory rate, and temperature) were similar at each district, including the urban and rural areas.

\section{Immunogenicity}

Pre-vaccination seropositivity was $76.4 \%$ in 1,329 (ITT) subjects, which is similar to the results seen in previous published studies [9-13]. This shows that nearly one quarter of the population between the ages of 12 and 15 years in Maharashtra remains susceptible to rubella. The Solapur and Latur districts have shown the lowest percent seroprotection (around $68 \%$ ). From the total study cohort, it was observed that the urban population had a comparatively better immune status than that of the rural population $(80.2 \%$ versus $73.1 \%)$, the difference being statistically significant. However, this is not a very comforting picture, as these girls are likely to shoulder the responsibility of childbearing in coming years and it is vital that they should have immunity until that time. Also, considerable variation with respect to seropositivity was observed within the districts (Table 1).

Following vaccination, $99.7 \%$ subjects became sero protected [Table 2]. Each cohort from the urban districts showed $100 \%$ sero protection whereas for the rural cohorts, three districts were very near to $100 \%$. For all individual districts, the GMT between pre and post vaccination was statistically significant [Table 3].

\section{Safety}

In the sero surveys conducted earlier in India, the recording of adverse events was limited and not a priority; however, we followed the subjects for 6 to 8 weeks for occurrence of any adverse event, following vaccination.

Intensity and severity of adverse events were measured and categorized for pain at the injection site, redness, swelling and fever (Table 4). Local reactions such as pain at the injection site, redness, and swelling were determined by the physician to be certainly related to vaccination. Two cases $(15.4 \%)$ of fever were determined to be certainly related and 11 cases $(84.6 \%)$ as probably related to the vaccine. One instance of marked but transient joint pain was found. The timing of onset and the fact that similar symptoms are observed in adult women suggested the probable relationship with the vaccine. It is suggested that physicians should be alert for occasional joint symptoms, especially in pre-pubertal rubella vaccine recipients. Rash and pruritus reported by a subject 
Table 1. Baseline rubella seropositivity

\begin{tabular}{|c|c|c|c|c|c|c|c|c|c|}
\hline \multirow[t]{3}{*}{ District } & \multicolumn{3}{|c|}{ Urban } & \multicolumn{3}{|c|}{ Rural } & \multicolumn{3}{|c|}{ Total } \\
\hline & \multirow{2}{*}{$\mathbf{N}$} & \multicolumn{2}{|c|}{ Seropositive } & \multirow{2}{*}{$\mathbf{N}$} & \multicolumn{2}{|c|}{ Seropositive } & \multirow{2}{*}{$\mathbf{N}$} & \multicolumn{2}{|c|}{ Seropositive } \\
\hline & & No. & $\%$ & & No. & $\%$ & & No. & $\%$ \\
\hline Ahmednagar & 36 & 34 & 94.4 & 54 & 37 & 68.5 & 90 & 71 & 78.8 \\
\hline Beed & 60 & 37 & 61.7 & 59 & 49 & 83.1 & 119 & 86 & 72.2 \\
\hline Dhule & 54 & 46 & 85.2 & 59 & 46 & 78.0 & 113 & 92 & 81.4 \\
\hline Jalna & 56 & 47 & 83.9 & 65 & 45 & 69.2 & 121 & 92 & 76.0 \\
\hline Kolhapur & 43 & 34 & 79.1 & 55 & 46 & 83.6 & 98 & 80 & 81.6 \\
\hline Latur & 32 & 21 & 65.6 & 57 & 40 & 70.2 & 89 & 61 & 68.5 \\
\hline Nashik & 67 & 53 & 79.1 & 61 & 49 & 80.3 & 128 & 102 & 79.7 \\
\hline Nandurbar & 60 & 51 & 85.0 & 58 & 37 & 63.8 & 118 & 88 & 74.5 \\
\hline Pune & 52 & 47 & 90.4 & 55 & 34 & 61.8 & 107 & 81 & 75.7 \\
\hline Satara & 55 & 49 & 89.1 & 60 & 43 & 71.7 & 115 & 92 & 80.0 \\
\hline Solapur & 57 & 43 & 75.4 & 65 & 41 & 63.1 & 122 & 84 & 68.8 \\
\hline Osmanabad & 55 & 41 & 74.5 & 54 & 46 & 85.2 & 109 & 87 & 79.8 \\
\hline All Districts & 627 & 503 & 80.2 & 702 & 513 & 73.1 & 1329 & 1016 & 76.4 \\
\hline
\end{tabular}

Table 2. Post-vaccination rubella seropositivity

\begin{tabular}{|c|c|c|c|c|c|c|c|c|c|}
\hline \multirow[t]{3}{*}{ District } & \multicolumn{3}{|c|}{ Urban } & \multicolumn{3}{|c|}{ Rural } & \multicolumn{3}{|c|}{ Total } \\
\hline & \multirow{2}{*}{$\mathbf{N}$} & \multicolumn{2}{|c|}{ Seropositive (\%) } & \multirow{2}{*}{$\mathbf{N}$} & \multicolumn{2}{|c|}{ Seropositive (\%) } & \multirow{2}{*}{$\mathbf{N}$} & \multicolumn{2}{|c|}{ Seropositive (\%) } \\
\hline & & Baseline & Post-vac & & Baseline & Post-vac & & Baseline & Post-vac \\
\hline Ahmednagar & 27 & 92.6 & 100 & 33 & 63.6 & 100 & 60 & 76.6 & 100 \\
\hline Beed & 55 & 61.8 & 100 & 56 & 85.7 & 100 & 111 & 73.8 & 100 \\
\hline Dhule & 50 & 84.0 & 100 & 55 & 78.2 & 100 & 105 & 80.9 & 100 \\
\hline Jalna & 46 & 80.4 & 100 & 43 & 69.8 & 100 & 89 & 75.3 & 100 \\
\hline Kolhapur & 35 & 85.7 & 100 & 52 & 82.7 & 100 & 87 & 83.9 & 100 \\
\hline Latur & 32 & 65.6 & 100 & 52 & 69.2 & 100 & 84 & 67.8 & 100 \\
\hline Nashik & 61 & 80.3 & 100 & 56 & 80.4 & 100 & 117 & 80.3 & 100 \\
\hline Nandurbar & 45 & 86.7 & 100 & 43 & 55.8 & 97.7 & 88 & 71.5 & 98.8 \\
\hline Pune & 43 & 88.4 & 100 & 52 & 61.5 & 100 & 95 & 73.6 & 100 \\
\hline Satara & 54 & 90.7 & 100 & 58 & 72.4 & 98.3 & 112 & 81.2 & 99.1 \\
\hline Solapur & 49 & 75.5 & 100 & 61 & 63.9 & 98.4 & 110 & 69.0 & 99.1 \\
\hline Osmanabad & 50 & 76.0 & 100 & 51 & 84.3 & 100 & 101 & 80.2 & 100 \\
\hline All Districts & 547 & 80.3 & 100 & 612 & 72.9 & 99.5 & 1159 & 76.3 & 99.7 \\
\hline
\end{tabular}

were determined to be possibly related to the vaccine. The complaint of giddiness was not related to the vaccine and hence termed as unlikely. All reported adverse events were transient and the patients recovered with or without concomitant medication within 48 hours. All the adverse events resolved completely, without any sequelae.

\section{Discussion}

Serological surveys play a definite role in defining infectious disease epidemiology and they also help policy makers to decide the health policies in order to contain the consequences of disease.
Rubella is a disease that can be studied by performing serological tests and then determining its potential health impact. Although rubella infection per se is a mild, exanthematous, febrile episode, its occurrence in pregnant women is a potentially threatening event as the fetus is put at risk of developing congenital rubella syndrome or intrauterine death or even premature birth. This is preventable as a highly effective vaccine is available for the purpose. However, to make a policy decision about implementing the vaccination programme with rubella/rubella containing vaccines, it is necessary 
Table 3. Post-vaccination geometric mean titre

\begin{tabular}{|c|c|c|c|c|c|c|c|c|c|}
\hline \multirow[t]{2}{*}{ District } & \multirow[t]{2}{*}{$\mathbf{N}$} & \multicolumn{2}{|c|}{$\begin{array}{c}\text { GMT } \\
(95 \% \text { CI })\end{array}$} & \multirow[t]{2}{*}{$\mathbf{N}$} & \multicolumn{2}{|c|}{$\begin{array}{c}\text { GMT } \\
(95 \% \text { CI })\end{array}$} & \multirow[t]{2}{*}{$\mathbf{N}$} & \multicolumn{2}{|c|}{$\begin{array}{c}\text { GMT } \\
(95 \% \text { CI) }\end{array}$} \\
\hline & & Baseline & Post-vac & & Baseline & Post-vac & & Baseline & Post-vac \\
\hline Ahmednagar & 27 & $\begin{array}{c}78.29 \\
(54.16- \\
113.17)\end{array}$ & $\begin{array}{c}124.93 \\
(112.93- \\
138.21)\end{array}$ & 33 & $\begin{array}{c}19.83 \\
(7.62- \\
51.56)\end{array}$ & $\begin{array}{c}144.95 \\
(129.05- \\
162.82)\end{array}$ & 60 & $\begin{array}{c}36.78 \\
(20.85- \\
64.90)\end{array}$ & $\begin{array}{c}135.57 \\
(125.29- \\
146.70)\end{array}$ \\
\hline Beed & 55 & $\begin{array}{c}26.96 \\
(14.45- \\
50.28)\end{array}$ & $\begin{array}{c}164.23 \\
(152.83- \\
167.48)\end{array}$ & 56 & $\begin{array}{c}73.40 \\
(45.95- \\
117.24)\end{array}$ & $\begin{array}{c}139.93 \\
(150.41- \\
170.05)\end{array}$ & 111 & $\begin{array}{c}44.68 \\
(29.97- \\
66.62)\end{array}$ & $\begin{array}{c}162.04 \\
(154.58- \\
169.87)\end{array}$ \\
\hline Dhule & 50 & $\begin{array}{c}51.26 \\
(36.27- \\
72.43)\end{array}$ & $\begin{array}{c}94.75 \\
(87.43- \\
102.69)\end{array}$ & 55 & $\begin{array}{c}19.58 \\
(12.70- \\
30.19)\end{array}$ & $\begin{array}{c}85.54 \\
(71.75- \\
101.97)\end{array}$ & 105 & $\begin{array}{c}30.96 \\
(23.06- \\
41.58)\end{array}$ & $\begin{array}{c}89.81 \\
(81.27- \\
99.24)\end{array}$ \\
\hline Jalna & 46 & $\begin{array}{c}48.73 \\
(30.44- \\
78.01)\end{array}$ & $\begin{array}{c}128.98 \\
(116.30- \\
143.05)\end{array}$ & 43 & $\begin{array}{c}25.05 \\
(11.81- \\
53.13)\end{array}$ & $\begin{array}{c}139.88 \\
(127.31- \\
153.68)\end{array}$ & 89 & $\begin{array}{c}35.33 \\
(22.79- \\
54.78)\end{array}$ & $\begin{array}{c}134.14 \\
(125.06- \\
143.87)\end{array}$ \\
\hline Kolhapur & 35 & $\begin{array}{c}59.12 \\
(32.25- \\
108.40)\end{array}$ & $\begin{array}{c}145.44 \\
(134.99- \\
156.70)\end{array}$ & 52 & $\begin{array}{c}52.76 \\
(30.12- \\
92.42)\end{array}$ & $\begin{array}{c}158.67 \\
(147.48- \\
170.70)\end{array}$ & 87 & $\begin{array}{c}55.23 \\
(36.63- \\
83.28)\end{array}$ & $\begin{array}{c}153.21 \\
(145.25- \\
161.60)\end{array}$ \\
\hline Latur & 32 & $\begin{array}{c}25.91 \\
(10.97- \\
61.18)\end{array}$ & $\begin{array}{c}142.02 \\
(130.63- \\
154.41)\end{array}$ & 52 & $\begin{array}{c}27.00 \\
(13.44- \\
54.23)\end{array}$ & $\begin{array}{c}155.77 \\
(142.65- \\
170.09)\end{array}$ & 84 & $\begin{array}{c}26.58 \\
(15.56- \\
45.41)\end{array}$ & $\begin{array}{c}150.38 \\
(141.16- \\
160.21)\end{array}$ \\
\hline Nashik & 61 & $\begin{array}{c}49.57 \\
(29.31- \\
83.83)\end{array}$ & $\begin{array}{c}143.20 \\
(132.51- \\
154.77)\end{array}$ & 56 & $\begin{array}{c}38.51 \\
(22.38- \\
66.27)\end{array}$ & $\begin{array}{c}126.00 \\
(110.18- \\
144.10)\end{array}$ & 117 & $\begin{array}{c}43.93 \\
(30.11- \\
64.09)\end{array}$ & $\begin{array}{r}134.70 \\
(124.75- \\
145.43)\end{array}$ \\
\hline Nandurbar & 45 & $\begin{array}{c}72.43 \\
(45.32- \\
115.76)\end{array}$ & $\begin{array}{c}143.95 \\
(131.77- \\
157.25)\end{array}$ & 43 & $\begin{array}{c}16.91 \\
(7.50- \\
38.12)\end{array}$ & $\begin{array}{c}161.06 \\
(135.87- \\
190.93)\end{array}$ & 88 & $\begin{array}{c}35.58 \\
(21.90- \\
57.79)\end{array}$ & $\begin{array}{c}152.07 \\
(138.37- \\
167.13)\end{array}$ \\
\hline Pune & 43 & $\begin{array}{c}47.66 \\
(31.05- \\
73.17)\end{array}$ & $\begin{array}{c}100.14 \\
(92.28- \\
108.67)\end{array}$ & 52 & $\begin{array}{c}17.82 \\
(11.70- \\
27.17)\end{array}$ & $\begin{array}{c}84.65 \\
(76.86- \\
93.23)\end{array}$ & 95 & $\begin{array}{c}27.82 \\
(20.28- \\
38.16)\end{array}$ & $\begin{array}{c}91.34 \\
(85.47- \\
97.61)\end{array}$ \\
\hline Satara & 54 & $\begin{array}{c}56.16 \\
(43.83- \\
71.96)\end{array}$ & $\begin{array}{c}107.47 \\
(95.81- \\
120.55)\end{array}$ & 58 & $\begin{array}{c}21.74 \\
(12.37- \\
38.22)\end{array}$ & $\begin{array}{c}95.79 \\
(78.28- \\
117.22)\end{array}$ & 112 & $\begin{array}{c}34.36 \\
(24.75- \\
47.68)\end{array}$ & $\begin{array}{c}101.26 \\
(89.94- \\
114.00)\end{array}$ \\
\hline Solapur & 49 & $\begin{array}{c}34.22 \\
(24.07- \\
48.64)\end{array}$ & $\begin{array}{c}143.41 \\
(133.48- \\
154.08)\end{array}$ & 61 & $\begin{array}{c}22.79 \\
(16.89- \\
30.75)\end{array}$ & $\begin{array}{c}61.35 \\
(54.25- \\
69.37)\end{array}$ & 110 & $\begin{array}{c}27.31 \\
(21.68- \\
34.41)\end{array}$ & $\begin{array}{c}89.55 \\
(80.70- \\
100.03)\end{array}$ \\
\hline Osmanabad & 50 & $\begin{array}{c}46.13 \\
(31.49- \\
67.59)\end{array}$ & $\begin{array}{c}123.05 \\
(111.77- \\
135.48)\end{array}$ & 51 & $\begin{array}{c}42.47 \\
(30.66- \\
58.83)\end{array}$ & $\begin{array}{c}90.99 \\
(82.56- \\
100.29)\end{array}$ & 101 & $\begin{array}{c}44.25 \\
(34.48- \\
56.78)\end{array}$ & $\begin{array}{c}105.64 \\
(98.06- \\
113.81)\end{array}$ \\
\hline All Districts & 547 & $\begin{array}{c}46.54 \\
(40.54- \\
53.43)\end{array}$ & $\begin{array}{c}128.45 \\
(124.81- \\
132.18)\end{array}$ & 612 & $\begin{array}{c}28.73 \\
(24.48- \\
33.73)\end{array}$ & $\begin{array}{c}113.80 \\
(108.85- \\
118.97)\end{array}$ & 1159 & $\begin{array}{c}36.08 \\
(32.40- \\
40.17)\end{array}$ & $\begin{array}{r}120.49 \\
(117.25- \\
123.82)\end{array}$ \\
\hline
\end{tabular}


Table 4. Adverse events details

\begin{tabular}{|c|c|c|c|c|}
\hline Sr. No. & Adverse Event & No. of AEs & $\%$ of AEs & $95 \%$ CI \\
\hline \multirow[t]{3}{*}{1} & Pain & 11 & 0.83 & $0.41-1.48$ \\
\hline & Grade 1 & 6 & 54.55 & $23.38-83.25$ \\
\hline & Grade 2 & 5 & 45.45 & $16.75-76.62$ \\
\hline \multirow[t]{3}{*}{2} & Redness & 3 & 0.23 & $0.05-0.66$ \\
\hline & $>0.0 \mathrm{~cm}-<2.5 \mathrm{~cm}$ & 2 & 66.66 & $9.43-99.16$ \\
\hline & $>2.5 \mathrm{~cm}-<5 \mathrm{~cm}$ & 1 & 33.33 & $0.84-90.57$ \\
\hline \multirow[t]{3}{*}{3} & Swelling & 6 & 0.45 & $0.17-0.98$ \\
\hline & $>0.0 \mathrm{~cm}-<2.5 \mathrm{~cm}$ & 4 & 66.66 & $22.28-95.67$ \\
\hline & $>2.5 \mathrm{~cm}-<5 \mathrm{~cm}$ & 2 & 33.33 & $4.33-77.72$ \\
\hline 4 & Nodule & 0 & 0.00 & $0.00-0.28$ \\
\hline \multirow[t]{3}{*}{5} & Fever & 13 & 0.98 & $0.52-1.67$ \\
\hline & $<38.0{ }^{0} \mathrm{C}$ & 3 & 23.08 & $5.04-53.81$ \\
\hline & 38.0 to $38.4{ }^{0} \mathrm{C}$ & 10 & 76.92 & $46.19-94.96$ \\
\hline 6 & Rash & 1 & 0.08 & $0.00-0.42$ \\
\hline 7 & Joint Pain & 1 & 0.08 & $0.00-0.42$ \\
\hline 8 & Muscle Pain & 0 & 0.00 & $0.00-0.29$ \\
\hline 9 & Lymphadenopathy & 0 & 0.00 & $0.00-0.29$ \\
\hline 10 & Giddiness & 5 & 0.38 & $0.12-0.88$ \\
\hline 11 & Pruritus & 1 & 0.08 & $0.00-0.42$ \\
\hline
\end{tabular}

to generate background data on the serological status of women and adolescent girls in the childbearing age group.

We planned this study to determine the serological status of rubella antibodies in adolescent girls, who probably had no prior exposure to rubella vaccine or infection. All the girls who participated in the survey were vaccinated with the rubella vaccine at enrollment, irrespective of serological status. This design helped us to vaccinate the maximum number of girls as there would be a greater chance of discontinuation if only serologically negative girls were to be vaccinated.

Considering the fact that earlier studies in India have been conducted on a smaller sample size and in other states, we planned to obtain a robust database that would represent the rural as well as the urban population of Maharashtra, an Indian state. It has 35 districts out of which we conducted this survey in 12 districts and included both the urban as well as the rural population of each district. We assume that this is a representative sample with respect to its implication for making national policy for rubella vaccination.

It is noteworthy that the majority of girls get protection until they attain adolescence; however, not all are protected and therefore some women remain susceptible to infection during pregnancy. The plausible cause for acquired protection seems to be the acquisition of rubella infection in early years of life. In our study, though all efforts were made to include only those girls who had no previous infection with rubella, the enrolment was based on the history supplied by the parents; therefore, it is very likely that some of these girls might have been exposed to the virus, resulting in the development of protective IgG titres. Rubella infection is often not recorded, and also it is difficult to diagnose clinically as the illness may present atypically.

On analyzing the data, no significant difference was observed between the rural and urban populations. However, there was a wide variation when the percentage of protection observed in different districts was considered $(68.5 \%$ for Latur and $81.6 \%$ for Kolhapur). Such regional variations 
have also been observed in earlier serological surveys. Variations related to socioeconomic status, as reported in earlier surveys, were also observed. The rubella vaccine has not been introduced into the

National Immunization schedule in India, which probably explains why none of the girls included in this study gave history of immunization against rubella. This undoubtedly shows that, in India, the need for immunization to control rubella infection and congenital rubella syndrome has not yet been recognized.

As of December 2009, a total of 130 WHO member states had introduced RCV, a $57 \%$ increase from 83 member states in 1996. In addition, goals to eliminate rubella and CRS have been established in the WHO Region of the Americas (by 2010) and the WHO European Region (by 2015); furthermore, the WHO Western Pacific Region has established targets for accelerated rubella control and CRS prevention by 2015 [14]. More than $90 \%$ of the countries in North America and in the European region have included rubella in routine immunization. Thus there remains a great potential to improve coverage as well as further reduce morbidity and mortality through more widespread introduction of currently available rubella vaccines, particularly in Asia and Africa.

It has been a decade since many newer conjugate vaccines have been introduced and given total attention by pediatricians and national health advisors. Although rubella vaccine is safe and effective, clear policy regarding rubella immunization of children either at 15 months or young girls at 9 to 12 years has not been outlined in India. This study shows that rubella virus infection is prevalent in Maharashtra and almost 25\% girls reach childbearing age without acquiring natural immunity against the disease. Studies conducted across India suggest similar baseline information on the susceptibility profile of women of childbearing age.

Incorporation of RCV into national childhood immunization schedules is both cost-beneficial and cost-effective [15]. In introducing rubella containing vaccines ( $R C V s), M R$ and MMR vaccines can easily replace single-antigen measles vaccines in routine childhood immunization schedules. The substantial morbidity and cost resulting from infants born with CRS and the ease of introduction of RCVs into the routine vaccination program clearly indicate that rubella vaccine should be introduced in the National Immunization Programme in India to ensure high vaccination coverage.

Rubella and CRS are vastly under-recognized and under-reported through routine disease surveillance systems. To raise the immunity against rubella and to prevent the risk of CRS in newborns we recommend that the guidelines for vaccination as set out by the World Health Organization be followed.

\section{Acknowledgement}

We thank the all the subjects, their parents/guardians and the principals of the schools who participated in this study. We gratefully acknowledge the work and contribution of the district coordinators, medical and para-medical staff of the KEM Hospital research Centre during the study, and Manipal Acunova, Bangalore, for the laboratory services. We thank Prof. Heikki Peltola for offering insightful comments and constructive criticism, and Dr. B. Kishore Kumar for the statistical analysis of the data and invaluable editorial assistance. Special thanks to the IMPACT foundation, United Kingdom, for the logistics and support during the study.

\section{References}

1. World Health Organization (2000) Position paper Rubella vaccine. Weekly Epidemiological Record, No. 20, 19 May 2000; 75: 161-172.

2. Vijaylakshmi P, Anuradha R, Prakash K, Narendran K, Ravindran M, Prajna L, Brown D, Robertson SE (2004) Rubella sero-surveys at three Arvind Eye Hospitals in Tamil Nadu, India. Bulletin of the World Health Organization 82: 259-64.

3. Rai A, Kumari S, Khare S, Gandhoke I, Bhatia R, Datta KK (19950 Maternal viral infections and implications in Congenital defects of new borns. J Basic and Applied biomedicine 3: 1-9.

4. Khare S, Banerjee K, Padbidri V, Rai A, Kumar S (1987) Lower immunity status of rubella virus infection in pregnant women. J Com Dis 19: 391-395.

5. Yadav S, Gupta S, Kumari S (1995) Sero-prevalence of rubella in women of reproductive age group. Indian J Pathol Microbiol 38: 139-142.

6. Gupta E, Dar L, Broor S (2006) Sero-prevalence of rubella in pregnant women in Delhi, India. Indian J Med Res 123: 833-835.

7. Robertson SE, Cutts FT, Samuel r, Diaz-Ortega JL (1997) Control of rubella and congenital rubella syndrome (CRS) in developing countries, Part 2: vaccination against rubella. Bulletin of the World Health Organization 75: 69-80.

8 Measles, Mumps, and Rubella: Vaccine Use and Strategies for Elimination of Measles, Rubella, and Congenital Rubella Syndrome and Control of Mumps: Recommendations of the Advisory Committee on Immunization Practices (ACIP). MMWR. May 22, 1998/ Vol. 47/ No. RR-8.

9. Bhaskaram P, Ramalakshmi BA, Ramaraju LA, Raman L (1991) Need for protection against Rubella in India. Indian J Pediatr 58: 811-814.

10. Chakrabarty MS, Das BC, Gupta B, Sarkar JK (1975) Rubella as an aetiological factor for congenital malformation in Calcutta: A serological study. Indian J Med Res63: 14381445.

11. Seth P, Balaya S, Mohapatra LN (1971) Seroepidemiological study of Rubella infection in female subjects of Delhi and its surrounding villages. Indian J Med 
Res 59: 190-194.

12. N Singla, N Jindal, A Aggarwal (2004) The seroepidemiology of rubella in Amritsar (Punjab), Indian Journal of Medical Microbiology 22: 61-63.

13. Hitt Sharma, Sunil Chowdhari, Tilak Raj Raina, Subodh Bhardwaj, Gajanan Namjoshi, Sameer Parekh (2010) A serosurvey, immunogenicity and safety of Rubella vaccine in peri-pubertal, seronegative Indian schoolgirls girls aged 1118 years. Indian Journal of Community Medicine 35:134137.

14. The goal of eliminating measles and rubella and prevention of CRS (2010) WHO Regional Committee meeting, Europe. September 2010.

15. Hinman AR, Irons B, Lewis M, Kandola K (2001) Economic analyses of rubella and rubella vaccines: a global review. Bull World Health Organ. 80: 264-270.

\section{Corresponding author}

Dr. Hitt J Sharma

Medical Affairs Department

Serum Institute of India Ltd

212/2, Hadapsar, Pune 411028, India

Telephone: + 91.20.26602451; Fax: +91.20.26998146;

Email:drhjs@seruminstitute.com

Conflict of interests: The study was funded by the Serum Institute of India Ltd., Pune, of which Drs HJS, SVK, SSJ, RMD, SSP, Mr SDS are employees and GSN was a former employee. They were responsible for the study design and contributed to the implementation, monitoring, analysis and interpretation of the data. Dr. VSP (Principal Investigator) and Mr. ADD (Study Coordinator) of KEM Hospital Research Centre, Pune, performed the study procedures and were involved in the acquisition, analysis and interpretation of data. They had no financial interest in the vaccine or its manufacturer but received research funding to undertake the study. 